Space shuttle

\title{
Discovery takes off at last
}

\section{Washington}

OfFICIALS of the National Aeronautical and Space Administration (NASA) could almost be heard breathing a collective sigh of relief last week when the temperamental shuttle orbiter Discovery finally cleared the launch tower at Kennedy Space Center, Florida, on 30 August. Two previous launch attempts were aborted with the crew already strapped in and ready to go, and a scheduled launch on 29 August was called off after deficiencies were found in computer software controlling critical flight functions. NASA has tried to keep its commercial customers happy by rescheduling satellite deployments, but at the back of everyone's mind is the knowledge that NASA will now be able to launch only 6 shuttle flights this year even if there are no further problems. Originally 10 were planned.

The 29 August attempt was abandoned because simulations confirmed that under certain emergency conditions (such as the failure of one of the five on-board generalpurpose computers), commands to the shuttle's "major event controller" could be delayed by as much as one second, enough for them to be rejected. The controller switches such critical events as the separation of the shuttle's external fuel tank and solid-fuel booster rockets, not to mention the bolts that secure the orbiter to the launch pad. NASA stresses that the postponement was a "safety first" decision and that a launch on 29 August would probably have been successful.

The difficulty appears to have been caused ultimately by inadequate testing procedures, since NASA insists that the onboard computers and the event controller had consistently performed to expectation in pre-flight simulations. The timing problem was first noticed during separate tests on software under development for a future shuttle mission. Parallel tests were then run on Discovery's computers and a similar effect confirmed: delays arose when the system had to deal with several events occurring almost simultaneously. The difficulty was rectified by a software patch, and go-ahead for the $\mathbf{3 0}$ August launch was given after a hastily-convened telephone conference of engineers. The inability to foresee exactly how a system of interacting computers will behave under non-standard conditions is presumably a problem that will not easily go away, because programs and hardware are continually being modified.

NASA was putting a brave face on the delay before last week's successful launch, and spokesmen were keen to point out that the last fault was only a potential one, and then only under worst-case conditions. Indeed, one suggested, it was to NASA's credit that it employed engineers able to raise such hypothetical problems. Whether
NASA's customers will be able to see further delays to the shuttle programme in quite this light remains to be seen. American Telephone and Telegraph (AT\&T), whose Telstar 3 satellite was reassigned to the present mission after the original failure to launch Discovery in June, declares itself content with the service given by NASA so far. However, AT\&T has not directly lost out as a result of NASA's latest rescheduling, which involved combining parts of the payloads of two separate missions. Less pleased, presumably, is Hughes Communications Services Inc., whose LEASAT-1 satellite has been held up by shuttle breakdowns, and a movie company whose cameras have had to be left behind.
Besides three commercial satellites, Discovery was carrying three major NASA experiments to provide information that will be needed for designing a space station. These employ a 30-metre long folding panel such as might be used for solar cells; on the present flight, however, most of the cells will be dummies. Besides characterizing the test cells' performance, the array will be used to gather information on structural vibrations. The shuttle is also carrying a continuous flow electrophoresis system belonging to McDonnell Douglas and Ortho Pharmaceuticals Inc., which will further examine the feasibility of commercial pharmaceutical manufacture in the zero-gravity environment of space. Earlier versions of this experiment flown in previous shuttle missions have given encouraging results, but the partners are not telling what exactly they have in mind to produce.

\section{Soviet space programme}

\section{Remote sensing in prospect}

FURTHER Comecon participation in the Soviet manned space programme is not foreseen in the "near future", Academician Vladimir Kotel'nikov told a press conference in Moscow last month. "Very broad and successful" international cooperation of the socialist countries of the world would, however, continue, he said. The "most impressive", he noted, will be the planned Vega mission to be launched in December, in which a two-part probe will be sent to Venus, one part then making a soft-landing on the planet and the rest continuing the rendezvous with Halley's comet, passing through the tail (at some $10,000 \mathrm{~km}$ from the head) in March 1986. The 130-kg Venus payload will include equipment developed in Bulgaria, Hungary, Poland and Czechoslovakia, and also Austria, France and West Germany. East Germany will provide the ground equipment for decoding the signals.

Apart from Vega, future Interkosmos projects seem likely to concentrate on what has always been one of the main aims of the programme: the use of remote sensing to aid the economies of the member nations. Photography from space of the homeland of the "guest" cosmonaut always formed part of the manned Interkosmos flights (although in the case of the Cuban cosmonaut this was apparently carried out by his Soviet "hosts" after he had returned to Earth). An Interkosmos symposium in Dushanbe last November, in which the Interkosmos cosmonauts took part, summed up the experience of the manned programme with particular emphasis on the value of remote sensing for locating mineral deposition and "enhancing" agricultural productivity.

The annual conference of leaders of the national coordinating bodies of Interkosmos, which met in Prague shortly before the Dushanbe conference, had likewise come out strongly in favour of remote sensing, the most practical route to making cooperation in space "more efficient".

A major step in implementing this joint remote sensing programme began last week in north-west Azerbaijan, involving representatives of all the European Comecon countries except Romania, working in conjunction with the three Soviet cosmonauts aboard Salyut-7. The ground team will make observations of the "spectral characteristics" of natural objects in the area (including the Mingechaur reservoir), which would be coordinated with aerial photographs and also photographs and spectrographs taken from the Salyut station. The orbital and airborne data are received by a special automated dataprocessing unit developed in Baku. The experiment is intended both to develop the "fundamentals of remote sensing of the environment" and also to provide practical recommendations for the utilization of agricultural land, pasture and reservoirs. For the Comecon participants, it is primarily a training exercise for future projects in which they will cooperate with Soviet space-crew passing over their homelands.

Interestingly, the experiment is coordinated not from Moscow or Baikonur, but by the Institute for the Remote Sensing of Natural Resources of the Azerbaijan Academy of Sciences. This institute has already obtained good results in predicting floods and mudslides in Azerbaijan, monitoring the state of the pastureland and forecasting the yield of the cotton crop. Delegation of coordination to the Academies of the Union Republics seems to be becoming a feature of the Interkosmos programme; the Vega mission is being coordinated by the Ukranian Academy.
Vera Rich 